\title{
Determination of Cadmium, Chromium, Copper and Lead in Sediments and Soil Samples by Electrothermal Atomic Absorption Spectrometry Using Zirconium Containing Chemical Modifiers
}

\author{
Orhan ACAR \\ TAEA, Saraykoy Ankara Nukleer Arastırma ve Egitim Merkezi, 06100 Ankara, Turkey
}

\begin{abstract}
A method for direct determination of cadmium, chromium, copper and lead in sediments and soil samples by electrothermal atomic absorption spectrometry using Zr, Ir, etylenediamine acetic acid (EDTA), Zr + EDTA, Ir + EDTA, $\mathrm{Zr}+\mathrm{Ir}$ and $\mathrm{Zr}+\mathrm{Ir}+$ EDTA as chemical modifiers in $0.5 \%(\mathrm{v} / \mathrm{v})$ Triton X-100 plus $0.2 \%(\mathrm{v} / \mathrm{v})$ nitric acid mixture used as diluent was developed. The effects of mass and mass ratio of modifiers on analytes in sample solutions were studied. The optimum masses and mass ratios of modifiers: $20 \mu \mathrm{g}$ of $\mathrm{Zr}, 4 \mu \mathrm{g}$ of Ir, $100 \mu \mathrm{g}$ of EDTA and $20 \mu \mathrm{g}$ of $\mathrm{Zr}+4 \mu \mathrm{g}$ of $\mathrm{Ir}$ $+100 \mu \mathrm{g}$ of EDTA, were used to enhance the analyte signals. Pyrolysis and atomization temperatures, atomization and background absorption profiles, characteristic masses, and detection limits of analytes in samples were compared in the presence or absence of a modifier. The detection limits and characteristic masses of analytes in a $0.5 \%(\mathrm{~m} / \mathrm{v})$ dissolved sample (dilution factor of $200 \mathrm{ml} \mathrm{g}^{-1}$ ) obtained with $\mathrm{Zr}+\mathrm{Ir}+$ EDTA are $8.0 \mathrm{ng} \mathrm{g}^{-1}$ and $1.2 \mathrm{pg}$ for Cd, $61 \mathrm{ng} \mathrm{g}^{-1}$ and $4.3 \mathrm{pg}$ for $\mathrm{Cr}, 32 \mathrm{ng} \mathrm{g}^{-1}$ and $23 \mathrm{pg}$ for $\mathrm{Cu}$, and $3.4 \mathrm{ng} \mathrm{g}^{-1}$ and $19 \mathrm{pg}$ for $\mathrm{Pb}$, respectively. The $\mathrm{Zr}+\mathrm{Ir}+$ EDTA modifier mixture was found to be preferable for the determination of analytes in sediment and soil-certified and standard reference materials. Depending on the sample type, the percent recoveries of analytes were increased from 81 to $103 \%$ by using the proposed modifier mixture; the results obtained are in good agreement with the certified values.
\end{abstract}

(Received August 1, 2005; Accepted November 1, 2005)

Direct determination of cadmium, chromium, copper and lead in various samples such as soils and sediments are very important and of great interest toxically, ecologically, agriculturally and environmentally. ${ }^{1-6}$ The main sources of $\mathrm{Cd}, \mathrm{Cr}, \mathrm{Cu}$ and $\mathrm{Pb}$, and their effects on living organisms have been explained in previous studies. $2,5,7,8$ One of the most used analytical techniques for the determination of low concentrations of these elements in such samples is electrothermal atomic absorption spectrometry (ETAAS), due to its high sensitivity, selectivity, simplicity and low detection limits. ${ }^{1,7-9}$ However, preatomization losses, especially for volatile analytes such as $\mathrm{Cd}$ and $\mathrm{Pb}$, high background absorption and interference effects of complex inorganic matrices such as soils and sediments are serious problems that complicate the direct determinations by ETAAS. In order to overcome these problems and to delay sample vaporization prior to the atomization, the platform technique combined with the addition of a suitable chemical modifier to the sample solution and a powerful background corrector have frequently been used.,10 The main purpose of using chemical modification in ETAAS is to stabilize the analyte elements at a pyrolysis temperature as high as possible by forming a chemical compound or an intermetallic phase,,$^{11}$ to remove most of the sample matrix efficiently without loss of analyte mass and to obtain less interference in the atomization step. In order to reduce the major interferences caused in real samples, we performed further investigations to find an effective chemical modifier. Tsalev et al. ${ }^{12}$ proposed a systematic review and detailed discussion on the characteristic features of chemical modifiers used in ETAAS. Volynsky ${ }^{13}$

E-mail: orhana@taek.gov.tr gave a critical review on the investigation of the mechanism of chemical modifiers. Different chemical modifiers, such as Pd$\mathrm{Mg}\left(\mathrm{NO}_{3}\right)_{2},{ }^{10,14} \mathrm{Pd}$ and Eu-Pd, ${ }^{7} \mathrm{Ir},{ }^{15,16} \mathrm{Zr},{ }^{16,17} \mathrm{Zr}$-Ir coating ${ }^{18}$ and EDTA,${ }^{19}$ were added to aqueous standards and samples by using platforms inserted into pyrolytically-coated graphite tubes. These additions and a Zeeman effect background corrector ${ }^{7,8,18}$ have been recommended to overcome the background absorption and interference effects in the sample matrix, and to improve the precision and accuracy. The EDTA complexes of metals act as a thermal stabilizer for the analyte during the preatomization stage in the atomizer and enhance the sensitivity of atomic absorption signals of the analytes. In addition, since EDTA acts as a masking agent, it eliminates any chloride, nitrate or sulfate interferences for the anayte..$^{20}$

In this work, Zr, Ir, EDTA, Zr + Ir, Zr + EDTA, Ir + EDTA and $\mathrm{Zr}+\mathrm{Ir}+$ EDTA chemical modifiers in $0.5 \%(\mathrm{v} / \mathrm{v})$ Triton $\mathrm{X}$ 100 plus $0.2 \%(\mathrm{v} / \mathrm{v})$ nitric acid mixture used as diluent were comprehensively studied to develop a new modifier mixture for the determinations of $\mathrm{Cd}, \mathrm{Cr}, \mathrm{Cu}$ and $\mathrm{Pb}$ in soil, coal fly ash and sediment-certified and standard reference materials. Pyrolysis and atomization temperatures, interference effects, characteristic masses $\left(m_{\mathrm{o}}\right)$ and limits of detection (LOD) were compared in the presence or absence of modifiers. The $\mathrm{Zr}+\mathrm{Ir}+$ EDTA proposed modifier mixture was applied to the determination of $\mathrm{Cd}, \mathrm{Cr}, \mathrm{Cu}$ and $\mathrm{Pb}$ in samples in order to verify the accuracy and precision of the proposed method. The addition of Triton $\mathrm{X}-100$ was considered to modify the physical properties of sample and of aqueous solutions, such as viscosity. Microwave oven-assisted sample dissolution was used for shortening the sample dissolution time and avoiding analyte losses and contaminations. Hydrofluoric acid was used for improving 
reproducibility and for removal of silicon during the heating cycle. ${ }^{21}$ The $\mathrm{Zr}$, Ir and $\mathrm{Zr}+\mathrm{Ir}$ coatings as permanent modifiers onto platform were not used, since atomization temperatures of $\mathrm{Cr}$ and $\mathrm{Cu}$ were higher than $2200^{\circ} \mathrm{C}$ and loss of modifier mass occured above this temperature..$^{9,15}$

\section{Experimental}

\section{Instrumentation}

All absorbance measurements were carried out using a 180/80 Model atomic absorption spectrometer (Hitachi, Japan), equipped with a graphite furnace (Hitachi 180/78) with a Zeeman effect background corrector, and an automatic data processing unit (180/205). Hitachi pyrolytic graphite-coated graphite tubes (P/N-190/6007) with graphite platforms (P/N190/6008) inserted were employed throughout the experiment; integrated absorbance (peak area) mode was used for signal evaluation. Hitachi $\mathrm{Cd}, \mathrm{Cr}, \mathrm{Cu}$ and $\mathrm{Pb}$ hollow cathode lamps were used as radiation sources. Resonance lines of hollow cathode lamps (Hitachi) used as radiation sources are $228.8 \mathrm{~nm}$ for $\mathrm{Cd}, 359.8 \mathrm{~nm}$ for $\mathrm{Cr}, 324.8 \mathrm{~nm}$ for $\mathrm{Cu}$ and $283.3 \mathrm{~nm}$ for $\mathrm{Pb}$, respectively. Operating currents and slits of all lamps are the same: $7.5 \mathrm{~mA}$ and $1.3 \mathrm{~nm}$, respectively. A $20 \mu \mathrm{l}$ volume of calibration or sample solution together with or without modifier solutions was injected into the platform by the autosampler (P/N-170/126). Argon (99.995\%, w/w) was used as the purge gas and the flow was interrupted during atomization. The optimized graphite furnace operating conditions and the temperature program for the determination of $\mathrm{Cd}, \mathrm{Cr}, \mathrm{Cu}$ and $\mathrm{Pb}$ are summarized in Table 1. A Varian Model 9176 recorder was used in a $20 \mathrm{mV} / \mathrm{FS}$ span in order to obtain atomization and background signal profiles. A Milestone Ethos Sel closedvessel microwave oven (MLS 1600, Italy) equipped with temperature and pressure control, a sample carousel and composite vessels, was used for decomposition of samples.

\section{Reagents and standards}

High-purity deionized water (resistivity $18 \mathrm{M} \Omega \mathrm{cm}$ ) obtained from an ultrapure water system (Nanopure Infinity, Barnstead, P/N-1161, Dubuque, USA) was used throughout to prepare the solutions. All acids and reagents were of analytical grade reagents unless otherwise stated. Nitric acid $(65 \%$, w/w), $\mathrm{HClO}_{4}\left(70-72 \%\right.$, w/w), $\mathrm{NH}_{3}(25 \%$, w/w), $\mathrm{HF}(40 \%$, w/w) and non-ionic surfactant Triton X-100 $(99.96 \%$, w/w) taken from Merck (Darmstadt, Germany) and EDTA $(99.85 \%$, w/w, FlukaGarantie, Switzerland) were used. All solutions prepared were stored in high-density polypropylene bottles. Plastic bottles, autosampler cups and glassware materials were cleaned by soaking in $20 \%(\mathrm{v} / \mathrm{v}) \mathrm{HNO}_{3}$ for two days and rinsing six times with ultra pure water, they were then dried. Autosampler washing solution containing $0.2 \%$ (v/v) $\mathrm{HNO}_{3}$ plus $0.2 \%(\mathrm{v} / \mathrm{v})$ Triton X-100 was used to clean the sampling capillary tip, to avoid any clogging of the autosampler pipette and to improve the dispersion of the sample solution onto the platform. ${ }^{22}$

Standard solutions of $\mathrm{Zr}$ and $\mathrm{Ir}\left(2.0 \mathrm{~g} \mathrm{l}^{-1}\right)$ were prepared from $706 \mathrm{mg} \mathrm{ZrOCl} 2 \cdot 8 \mathrm{H}_{2} \mathrm{O}$ (Merck) dissolved in $10 \% \mathrm{HCl}$ and 234 mg $\mathrm{IrO}_{2}$ (Merck) dissolved in $10 \%$ (v/v) $\mathrm{HNO}_{3}$ solution and diluted to each $100 \mathrm{ml}$ portion with deionized water after evaporation of acids. The EDTA solution (2\%, m/v) was prepared before measurements by dissolving $2.0 \mathrm{~g}$ EDTA in $2 \%$ $\mathrm{NH}_{3}$ solution and diluting to $100 \mathrm{ml}$ with deionized water.

Stock standard solutions of $\mathrm{Cd}, \mathrm{Cr}, \mathrm{Cu}$ and $\mathrm{Pb}\left(1.0 \mathrm{~g} \mathrm{l}^{-1}\right)$ obtained from BDH Chemicals (Poole, UK) were used. Calibration solutions were freshly prepared by successive
Table 1 Heating programs for the determination of $\mathrm{Cd}, \mathrm{Cr}, \mathrm{Cu}$ and $\mathrm{Pb}$ in samples with different modifiers

\begin{tabular}{ccccc}
\hline Step & Temperature ${ }^{\circ} \mathrm{C}$ & Ramp/s & Hold/s & $\begin{array}{c}\text { Ar flow rate/ } \\
\mathrm{ml} \mathrm{min}^{-1}\end{array}$ \\
\hline 1 & $50-130$ & 30 & - & 250 \\
2 & $130-200$ & 10 & 10 & 250 \\
3 & $200-$ Variable $^{\mathrm{a}}$ & 30 & 30 & 250 \\
4 & Variable $^{\mathrm{b}}$ & 0 & 5 & 0 \\
5 & Variable $^{\mathrm{c}}$ & 0 & 3 & 250 \\
\hline
\end{tabular}

a. See Table 2.

b. Optimum atomization temperatures found are $1500^{\circ} \mathrm{C}$ for $\mathrm{Cd}$, $2700^{\circ} \mathrm{C}$ for $\mathrm{Cr}$ and $\mathrm{Cu}$, and $2000^{\circ} \mathrm{C}$ for $\mathrm{Pb}$, respectively.

c. Cleaning temperatures used are $2650^{\circ} \mathrm{C}$ for $\mathrm{Cd}$ and $\mathrm{Pb}, 2800^{\circ} \mathrm{C}$ for $\mathrm{Cr}$ and $\mathrm{Cu}$, respectively.

dilution of the stock solutions to the desired concentrations in $0.2 \%(\mathrm{v} / \mathrm{v})$ nitric acid solution as diluent before use.

\section{Decomposition of samples by microwave digestion}

Buffalo river sediment 2704, estuarine sediment 1646a, San Joaquin soil 2709, Montana II soil 2711, coal fly ash 1633 b standard reference materials (SRMs) from the National Institute of Standards and Technology (NIST, Gaithersburg, MD, USA), and lake sediment SL-1 and soil SL-7 certified reference materials (CRMs) from International Atomic Energy Agency (IAEA, Vienna, Austria) were used for checking the accuracy and precision of the proposed method. Decomposition of samples was performed in a Milestone Ethos Sel microwave oven according to the following procedures described in previous works ${ }^{9,15,22,23}$ in three replicates.

A portion of each sample $(0.10-0.30 \mathrm{~g})$ was accurately weighed into a Teflon digestion vessel, then $2.0 \mathrm{ml}$ concentrated $\mathrm{HNO}_{3}, 1.0 \mathrm{ml}$ concentrated $\mathrm{HClO}_{4}$ and $1.0 \mathrm{ml} \mathrm{HF}$ were subsequently added to the vessel, with a gentle swirl of the acid mixture. The bomb was closed and placed inside the microwave oven. The applied microwave program included the steps: heating from room temperature to $130^{\circ} \mathrm{C}$ for $10 \mathrm{~min}$ and waiting at this temperature for $10 \mathrm{~min}$; heating from $130^{\circ} \mathrm{C}$ to $200^{\circ} \mathrm{C}$ for $10 \mathrm{~min}$ and holding for $20 \mathrm{~min}$; and turning off the microwave and waiting for $20 \mathrm{~min}$. After cooling to room temperature, the bomb cap was withdrawn, and the open vessel was placed on a hot plate. One milliliter of concentrated $\mathrm{HClO}_{4}$ was added and the sample was boiled nearly to dryness in order to evaporate the excess acids such as HF. If any residue remained, the decomposition procedure was repeated until it was dissolved completely. The final solution was transferred to 10,25 or $50 \mathrm{ml}$ volumetric flasks by washing the interior surface of digestion vessel with $2 \%(\mathrm{v} / \mathrm{v}) \mathrm{HNO}_{3}$ three times; the final acidity of the flask was adjusted to $0.2 \%(\mathrm{v} / \mathrm{v}) \mathrm{HNO}_{3}$.

After adding $2 \mathrm{ml} \mathrm{HNO}_{3}, 0.5 \mathrm{ml} \mathrm{HClO}_{4}$ and $0.5 \mathrm{ml} \mathrm{HF}$ into the two Teflon bombs, we also prepared blanks in conjuction with the digestion procedure described above for the samples. The bombs were washed four times with deionized water into 25 or $50 \mathrm{ml}$ volumetric flasks and diluted to the mark after heating on a hot plate nearly to dryness and cooling.

\section{Analytical procedures}

Sample solutions diluted with $0.2 \%$ (v/v) nitric acid plus $0.5 \%$ $(\mathrm{v} / \mathrm{v})$ Triton X-100 were used to obtain optimum parameters of modifiers for the determination of analytes in ETAAS. A 1-ml portion of an appropriate concentration of analyte in sample solution was mixed with $1 \mathrm{ml}$ of modifier solution $\left(2.0 \mathrm{~g} \mathrm{l}^{-1} \mathrm{Zr}\right.$, $0.4 \mathrm{~g} \mathrm{l}^{-1} \mathrm{Ir}, 2.0 \mathrm{~g} \mathrm{l}^{-1} \mathrm{Zr}+0.4 \mathrm{~g} \mathrm{l}^{-1} \mathrm{Ir}$ or $2.0 \mathrm{~g} \mathrm{l}^{-1} \mathrm{Zr}+0.4 \mathrm{~g} \mathrm{l}^{-1} \mathrm{Ir}+$ 

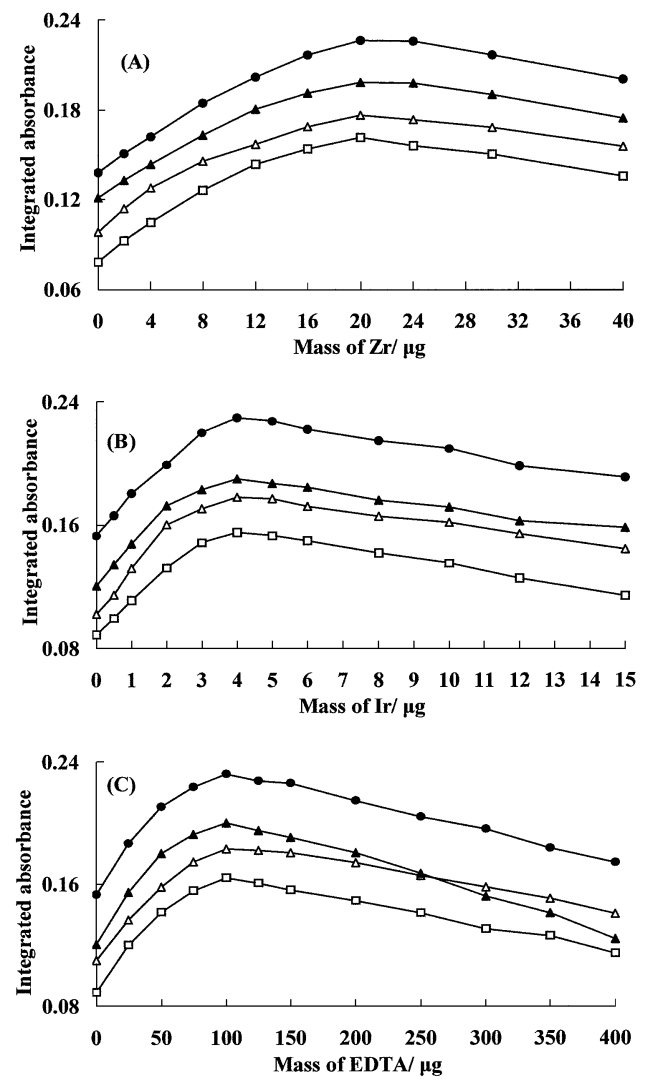

Fig. 1 Effect of mass of (A) Zr with fixed $4 \mu \mathrm{g}$ of Ir, (B) Ir with fixed $20 \mu \mathrm{g}$ of $\mathrm{Zr}$ and (C) EDTA with fixed $20 \mu \mathrm{g}$ of $\mathrm{Zr}+4 \mu \mathrm{g}$ of $\mathrm{Ir}$ modifier mixture on the absorbance values of $\mathrm{Cd}(\triangle)$ in buffalo river sediment $2704\left(2.28 \pm 0.12 \mu \mathrm{g} \mathrm{l}^{-1} \mathrm{Cd}\right), \mathrm{Cr}(\bullet)$ and $\mathrm{Cu}(\square)$ in estuarine

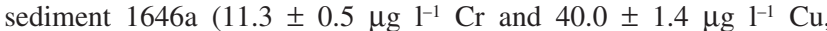
respectively), and $\mathrm{Pb}(\boldsymbol{\Lambda})$ in coal fly ash $1633 \mathrm{~b}\left(41.6 \pm 1.1 \mu \mathrm{g} \mathrm{l^{-1 } \mathrm { Pb } )}\right.$ sample solutions.

$10 \mathrm{~g} \mathrm{l}^{-1}$ EDTA) and $20 \mu \mathrm{l}$ of this mixed solution was injected into the platform inserted in a pyrolytic graphite-coated tube. The maximum absorbance values for analytes were found by changing the heating temperatures, ramp and hold times in preliminary studies. The optimized heating temperature program is given in Table 1. After a suitable concentration of analyte in aqueous or sample solution was mixed together with an appropriate concentration or concentration ratio of single and mixed modifiers or without a modifier, $20 \mu \mathrm{l}$ of the solution was also injected into the platform in order to obtain absorbance versus mass or mass ratio of modifier curves (Fig. 1), pyrolysis and atomization temperature curves (Fig. 2) and calibration graphs for analytes.

\section{Results and Discussion}

Optimization conditions of ETAAS by modifiers

Cadmium, $\mathrm{Cr}, \mathrm{Cu}$ and $\mathrm{Pb}$ are routinely determined in soils and sediments. Use of a chemical modifier is required for the determination of these elements, especially if high contents of concomitants are present in such samples. ${ }^{14}$ Optimization of ETAAS conditions such as effects of mass and mass ratio of modifiers on analytes and pyrolysis and atomization temperatures were investigated in sample solutions. The effect of mass and mass ratio of $\mathrm{Zr}, \mathrm{Ir}, \mathrm{Zr}+\mathrm{Ir}$ and $\mathrm{Zr}+\mathrm{Ir}+$ EDTA modifier mixture on the pyrolysis temperatures and absorbance
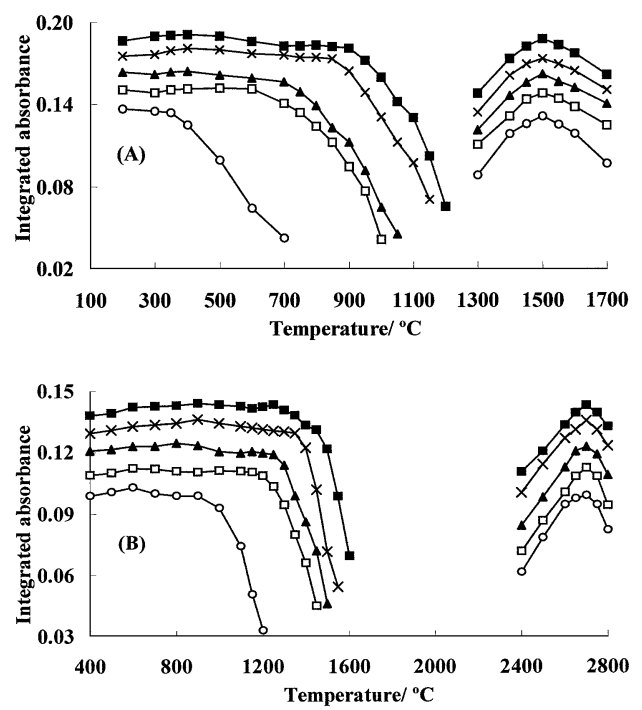

Fig. 2 Pyrolysis and atomization curves of (A) Cd in San Joaquin $2709\left(2.40 \pm 0.15 \mu \mathrm{g} \mathrm{l^{-1 }} \mathrm{Cd}\right)$ and $(\mathrm{B}) \mathrm{Cr}$ in soil SL-7 $\left(7.08 \mu \mathrm{g} \mathrm{l^{-1 }} \mathrm{Cr}\right)$ sample solutions with or without of modifiers. O, Without; $\boldsymbol{\Delta}, 20 \mu \mathrm{g}$ of $\mathrm{Zr}$; $\square, 4 \mu \mathrm{g}$ of Ir; $\times, 20 \mu \mathrm{g}$ of $\mathrm{Zr}+4 \mu \mathrm{g}$ of Ir; $\mathbf{\square}, 20 \mu \mathrm{g}$ of $\mathrm{Zr}+4 \mu \mathrm{g}$ of $\mathrm{Ir}+100 \mu \mathrm{g}$ of EDTA.

values of analytes in sample solutions were studied by preliminary experiments. Absorbance values found versus mass ratios of $\mathrm{Zr}+\mathrm{Ir}$ and $\mathrm{Zr}+\mathrm{Ir}+$ EDTA for analytes in buffalo river sediment $2704\left(2.28 \pm 0.12 \mu \mathrm{g} \mathrm{l^{-1 }} \mathrm{Cd}\right)$, estuarine sediment $1646 \mathrm{a}\left(11.3 \pm 0.5 \mu \mathrm{g} \mathrm{l^{-1 }} \mathrm{Cr}\right.$ and $40.0 \pm 1.4 \mu \mathrm{g} \mathrm{l}^{-1} \mathrm{Cu}$, respectively) and coal fly ash $1633 \mathrm{~b}\left(41.6 \pm 1.1 \mu \mathrm{g} \mathrm{l^{-1 }} \mathrm{Pb}\right)$ sample solutions at the pyrolysis temperatures were plotted. These plots are shown in Fig. 1 as examples. As can be seen, the optimum mass and mass ratios of the modifier components were found to be $20 \mu \mathrm{g}$ of $\mathrm{Zr}, 4 \mu \mathrm{g}$ of Ir, $100 \mu \mathrm{g}$ of EDTA and $20 \mu \mathrm{g}$ of $\mathrm{Zr}+4 \mu \mathrm{g}$ of $\mathrm{Ir}+100 \mu \mathrm{g}$ of EDTA. These values were compared with those reported in previous works ${ }^{17,19,24}$ and similar results were observed.

Pyrolysis and atomization temperature curves of analytes in sample solutions obtained in the presence or absence of modifiers using the heating program given in Table 1 are shown in Fig. 2 as examples. Atomization curves for analytes were obtained by measuring the absorbance values at various atomization temperatures, while the pyrolysis temperatures of analytes were kept constant in the presence or absence of modifiers. Maximum pyrolysis and atomization temperatures of analytes determined from these curves are given in Tables 1 and 2. As can be seen in Table 2 and Fig. 2, the pyrolysis temperatures of analytes obtained with $\mathrm{Zr}+\mathrm{Ir}+$ EDTA were higher than those obtained with $\mathrm{Zr}+\mathrm{Ir}$ and other components. In the presence of $100 \mu \mathrm{g}$ of EDTA together with $\mathrm{Zr}+\mathrm{Ir}$, the pyrolysis temperatures of analytes obtained are higher by $50^{\circ} \mathrm{C}$. Addition of EDTA dissolved in $\mathrm{NH}_{3}$ may be effective. Because metal ions in sample solution are masked by EDTA, formation of metal chloride on the surface of the tube during the drying step may be prevented, and elimination of ammonium chloride from the furnace may be promoted..$^{25}$ The maximum pyrolysis temperatures of analytes obtained with the $\mathrm{Zr}+\mathrm{Ir}+$ EDTA modifier mixture or without a modifier were compared with the results of previous studies ${ }^{17,24}$ and the small differences observed may be ascribed to the instrumental parameters or different tubes or platforms used. The pyrolysis temperatures obtained by $\mathrm{Zr}+\mathrm{Ir}+$ EDTA might be used to decrease most interferences and matrix components without any lost of analyte 
Table 2 Pyrolysis temperatures, characteristic masses and detection limits of cadmium, chromium, copper and lead obtained with different modifiers (dilution factor of $200 \mathrm{ml} \mathrm{g}^{-1}$ )

\begin{tabular}{|c|c|c|c|c|c|c|c|c|c|c|c|c|}
\hline \multirow{2}{*}{ Modifier } & \multicolumn{4}{|c|}{ Pyrolysis temperature $/{ }^{\circ} \mathrm{C}$} & \multicolumn{4}{|c|}{$m_{\mathrm{o}} / \mathrm{pg}$} & \multicolumn{4}{|c|}{$\mathrm{LOD} / \mathrm{ng} \mathrm{g}^{-1}$} \\
\hline & $\mathrm{Cd}$ & $\mathrm{Cr}$ & $\mathrm{Cu}$ & $\mathrm{Pb}$ & $\mathrm{Cd}$ & $\mathrm{Cr}$ & $\mathrm{Cu}$ & $\mathrm{Pb}$ & $\mathrm{Cd}$ & $\mathrm{Cr}$ & $\mathrm{Cu}$ & $\mathrm{Pb}$ \\
\hline Without & 350 & 1000 & 1000 & 900 & 2.4 & 6.4 & 43 & 37 & 31 & 94 & 56 & 6.4 \\
\hline EDTA & 350 & 1000 & 1000 & 900 & 2.2 & 6.2 & 39 & 34 & 27 & 86 & 53 & 5.6 \\
\hline $\mathrm{Ir}$ & 600 & 1200 & 1200 & 1050 & 2.0 & 6.1 & 35 & 31 & 25 & 81 & 49 & 5.1 \\
\hline $\mathrm{Zr}$ & 700 & 1250 & 1200 & 1050 & 1.8 & 5.2 & 34 & 29 & 23 & 76 & 43 & 4.9 \\
\hline $\mathrm{Ir}+\mathrm{EDTA}$ & 750 & 1300 & 1250 & 1100 & 1.6 & 5.1 & 32 & 26 & 18 & 71 & 39 & 4.4 \\
\hline $\mathrm{Zr}+\mathrm{EDTA}$ & 800 & 1300 & 1250 & 1100 & 1.5 & 4.8 & 31 & 24 & 16 & 68 & 38 & 4.2 \\
\hline $\mathrm{Zr}+\mathrm{Ir}$ & 850 & 1350 & 1300 & 1200 & 1.3 & 4.6 & 28 & 21 & 12 & 64 & 34 & 3.7 \\
\hline $\mathrm{Zr}+\mathrm{Ir}+\mathrm{EDTA}$ & 900 & 1400 & 1350 & 1250 & 1.2 & 4.3 & 23 & 19 & 8 & 61 & 32 & 3.4 \\
\hline
\end{tabular}

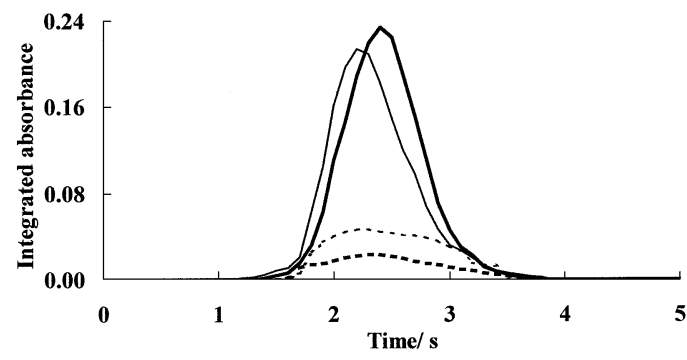

Fig. 3 Atomization and background profiles of $\mathrm{Pb}$ in lake sediment SL-1 $\left(42.1 \pm 8.3 \mu \mathrm{g} \mathrm{l}^{-1} \mathrm{~Pb}\right)$ sample solution obtained without $(-, \cdots \cdots \cdot)$ and with $20 \mu \mathrm{g}$ of $\mathrm{Zr}+4 \mu \mathrm{g}$ of $\mathrm{Ir}+100 \mu \mathrm{g}$ of EDTA $(-, \cdots \cdots \cdot)$ modifier mixture.

mass prior to atomization step. The optimum atomization temperatures of analytes given in Table 1 allow complete atomization of analytes in samples. Many of the sample solutions were diluted with $0.5 \%$ (v/v) Triton X-100 plus $0.2 \%$ $(\mathrm{v} / \mathrm{v})$ nitric acid mixture used as diluent before absorbance measurements because their background values were above the compensating capability of the Zeeman background corrector.

The typical atomization and background profiles of analytes in sample solutions with and without of modifiers plotted were comparatively investigeted to demonstrate how the modifier affects the signals of analytes. ${ }^{11,14,26}$ Figure 3 shows atomization/background profiles of $\mathrm{Pb}$ in the lake sediment SL$1\left(42.1 \pm 8.3 \mu \mathrm{g} \mathrm{l}^{-1} \mathrm{~Pb}\right)$ sample solution obtained with $\mathrm{Zr}+\mathrm{Ir}+$ EDTA modifier mixture or without a modifier as an example. As can be seen, the absorbance values of $\mathrm{Pb}$ obtained are higher and the background signals are lower in the presence of $\mathrm{Zr}+\mathrm{Ir}$ + EDTA than those obtained in the absence of a modifier. Signal/noise ratios of $\mathrm{Pb}$ obtained with $\mathrm{Zr}+\mathrm{Ir}+$ EDTA are higher than those obtained without a modifier. It was observed that the peak of $\mathrm{Pb}$ absorbance in the presence of $\mathrm{Zr}+\mathrm{Ir}+$ EDTA shifted to the later appearance time than in the absence of a modifier. ${ }^{11,26}$ With the addition of EDTA, a narrower, more symmetric atomic absorption profile was obtained. Generally, organic substances such as ascorbic acid ${ }^{27,28}$ and EDTA ${ }^{19,20,25}$ used as reducing agents are very efficient in reducing the modifiers and analytes to their free reactive metals at temperatures less than $800^{\circ} \mathrm{C}$ and therefore the stabilizing effect of a modifier is increased. ${ }^{11,28}$ The radicals and gases such as $\mathrm{H}_{2}, \mathrm{H}, \mathrm{HO}$, and $\mathrm{CO}$ produced by oxidizing organic substances may react with salt contents such as chloride or other ion interferences in samples. ${ }^{29}$

\section{Analytical figures of merit}

Determination of analytes in sample solutions with or without a modifier in $0.5 \%$ triton $\mathrm{X}-100$ plus $0.2 \% \mathrm{HNO}_{3}$ solution was performed using the calibration graph method, instead of the analyte addition technique. Calibration graphs were carried out against aqueous analyte standards with linear ranges extending up to $6 \mu \mathrm{g} \mathrm{l}^{-1}$ for $\mathrm{Cd}$, up to $25 \mu \mathrm{g} \mathrm{l}^{-1}$ for $\mathrm{Cr}$, and up to $80 \mu \mathrm{g} \mathrm{l^{-1 }}$ for $\mathrm{Cu}$ and $\mathrm{Pb}$ using the optimization parameters in Tables 1 and 2 , and the masses and mass ratios of modifiers. Calibration graphs were linear and all correlation coefficients $(r)$ for analytes were higher than 0.99 .

The characteristic mass $\left(m_{0}\right)$ is defined as the mass of analyte corresponding to 0.0044 abs unit. The limits of detection (LOD) are generally described as concentrations of analyte related to three times the standard deviation of absorbance units from blank solutions with or without modifier solution., ${ }^{411,30}$ The characteristic masses obtained for analytes, and detection limits calculated from 20 consecutive measurements of blank solutions $\left(0.5 \%(\mathrm{v} / \mathrm{v})\right.$ Triton X-100 plus $0.2 \%(\mathrm{v} / \mathrm{v}) \mathrm{HNO}_{3}$ ) for $0.5 \%(\mathrm{~m} / \mathrm{v})$ reference materials with or without of modifier, based on integrated absorbance, ${ }^{30,31}$ are summarized in Table 2. As can be seen, better $m_{\mathrm{o}}$ values and the lowest detection limits were obtained with $\mathrm{Zr}+\mathrm{Ir}+$ EDTA in $0.5 \%$ (v/v) Triton X-100 plus $0.2 \%(\mathrm{v} / \mathrm{v})$ nitric acid solution when all values were compared with each other. The $m_{\mathrm{o}}$ values found for $\mathrm{Cd}, \mathrm{Cr}$ and $\mathrm{Pb}$ are similar with the results obtained in the previous studies: 0.9 and $1.3 \mathrm{pg}$ for $\mathrm{Cd}^{8,9} 3.3 \mathrm{pg}$ for $\mathrm{Cr}^{7}$ and $18 \mathrm{pg}$ for $\mathrm{Pb}{ }^{9}$ Inconsistencies in results may be due to the instrumental and operating parameters used. The means of blank absorbance signals obtained with $\mathrm{Zr}+\mathrm{Ir}+$ EDTA using the temperature program and pyrolysis temperatures given in Tables 1 and 2 are 0.014 for $\mathrm{Cd}, 0.009$ for $\mathrm{Cr}, 0.012$ for $\mathrm{Cu}$ and 0.026 for $\mathrm{Pb}$, respectively. Based on the explanations above and the results obtained, $\mathrm{Zr}+\mathrm{Ir}+$ EDTA in $0.5 \%$ (v/v) Triton X-100 plus $0.2 \%$ (v/v) nitric acid mixture was proposed for the $\mathrm{Cd}, \mathrm{Cr}, \mathrm{Cu}$ and $\mathrm{Pb}$ determinations in soils, sediments and coal fly ash.

\section{Application}

An extensive application of the $\mathrm{Zr}+\mathrm{Ir}+$ EDTA modifier mixture in $0.5 \%$ (v/v) Triton X-100 plus $0.2 \%$ (v/v) nitric acid mixture proposed for the determinations of $\mathrm{Cd}, \mathrm{Cr}, \mathrm{Cu}$ and $\mathrm{Pb}$ in digested solid certified and reference materials was carried out to confirm the accuracy and performance of the method. Heating programs (Table 1), pyrolysis temperatures for analytes (Table 2), optimum mass and mass ratio of modifiers and the integrated absorbance mode were used. In all cases, the calibration was run against aqueous standard solutions in $0.5 \%$ (v/v) Triton X-100 plus $0.2 \%$ (v/v) nitric acid. The results of analytes found in samples are given in Table 3. They are 
Table 3 Cadmium, chromium, copper and lead determination in soil sediment reference materials using $\mathrm{Zr}+\mathrm{Ir}+$ EDTA modifier mixture (concentration $/ \mu \mathrm{g} \mathrm{g}^{-1}$ )

\begin{tabular}{|c|c|c|c|c|c|c|c|c|}
\hline \multirow{2}{*}{ Sample } & \multicolumn{2}{|c|}{$\mathrm{Cd}$} & \multicolumn{2}{|c|}{$\mathrm{Cr}$} & \multicolumn{2}{|c|}{$\mathrm{Cu}$} & \multicolumn{2}{|c|}{$\mathrm{Pb}$} \\
\hline & Certified & Found $^{\mathrm{a}}$ & Certified & Found $^{a}$ & Certified & Found $^{\mathrm{a}}$ & Certified & Found $^{\text {a }}$ \\
\hline SRM 2704 & $3.45 \pm 0.22$ & $3.40 \pm 0.16$ & $135 \pm 5$ & $133 \pm 3$ & $98.6 \pm 5.0$ & $95.2 \pm 4.0$ & $161 \pm 17$ & $158 \pm 8$ \\
\hline SRM 1646a & $0.15 \pm 0.01$ & $0.15 \pm 0.01$ & $40.9 \pm 1.9$ & $40.5 \pm 0.3$ & $10.01 \pm 0.34$ & $9.71 \pm 0.26$ & $11.7 \pm 1.1$ & $11.3 \pm 0.5$ \\
\hline SRM 2709 & $0.38 \pm 0.01$ & $0.37 \pm 0.01$ & $130 \pm 4$ & $127 \pm 3$ & $34.6 \pm 0.7$ & $33.7 \pm 1.1$ & $18.9 \pm 0.5$ & $19.2 \pm 0.6$ \\
\hline SRM 1633b & $0.78 \pm 0.01$ & $0.79 \pm 0.01$ & $198.2 \pm 4.7$ & $199 \pm 5$ & $112.8 \pm 2.6$ & $111 \pm 3$ & $68.2 \pm 1.1$ & $67.6 \pm 1.1$ \\
\hline SRM 2711 & $41.70 \pm 0.25$ & $40.1 \pm 1.2$ & $47^{\mathrm{b}}$ & $46 \pm 1$ & $114 \pm 2$ & $115 \pm 2$ & $1162 \pm 31$ & $1168 \pm 25$ \\
\hline CRM SL-7 & $1.3(1.1-2.7)^{\mathrm{b}}$ & $1.32 \pm 0.06$ & $60(49-74)$ & $62 \pm 2$ & $11(9-13)$ & $12.1 \pm 0.5$ & $60(55-71)$ & $64 \pm 2$ \\
\hline CRM SL-1 & $0.26 \pm 0.05$ & $0.25 \pm 0.03$ & $104 \pm 9$ & $106 \pm 5$ & $30.0 \pm 5.6$ & $30.6 \pm 1.6$ & $37.7 \pm 7.4$ & $37.1 \pm 1.8$ \\
\hline
\end{tabular}

a. Mean of eight replicate measurements of a sample solution with $95 \%$ confidence level, $\bar{X} \pm 2.36 s / \sqrt{n}$. b. Non certified.

presented as the average \pm confidence interval at $95 \%$ confidence level. As can be seen in Table 3, in the presence of $\mathrm{Zr}+\mathrm{Ir}+\mathrm{EDTA}$, the obtained results are in good agreement with the certified values and the recoveries obtained are in the range of $97-103 \%$. The standard deviations of the measurements decreased in the presence of $\mathrm{Zr}+\mathrm{Ir}+$ EDTA, and the accuracy and precision increased. The use of EDTA is useful for depressing or reducing the interferences such as chloride or nitrate ions as $\mathrm{HCl}(\mathrm{g})$ and $\mathrm{HNO}_{3}(\mathrm{~g})$ at low temperatures. The analytes in samples were also determined in the absence of a modifier; the percent recoveries found are lower than $88 \%$ (recovery range was $81-87 \%$ ) because the samples have highly complex matrices and interferences.

\section{Conclusion}

A method for direct determination of $\mathrm{Cd}, \mathrm{Cr}, \mathrm{Cu}$ and $\mathrm{Pb}$ in soils, sediments and coal fly ash digested from certified and reference materials containing high element constituents was proposed. Interference effects and analytical problems arising from the sample matrix were effectively reduced with $\mathrm{Zr}+\mathrm{Ir}+$ EDTA in $0.5 \%(\mathrm{v} / \mathrm{v})$ Triton $\mathrm{X}-100$ plus $0.2 \%(\mathrm{v} / \mathrm{v})$ nitric acid. The shape of the atomic absorption profiles obtained was symmetric. It can be expected that the $\mathrm{Zr}+\mathrm{Ir}+$ EDTA modifier mixture recommended will be applicable to the determinations of $\mathrm{Cd}$, $\mathrm{Cr}, \mathrm{Cu}$ and $\mathrm{Pb}$ in various samples such as soils and sediments although they have highly complex matrices.

\section{Acknowledgements}

The supports of the Turkish Atomic Energy Authority and the Ankara Nuclear Research and Training Center are gratefully acknowledged.

\section{References}

1. J. Sastre, A. Sahuquillo, M. Vidal, and G. Rauret, Anal. Chim. Acta, 2002, 462, 59.

2. V. Sandroni, C. M. M. Smith, and A. Donovan, Talanta, 2003, 60, 715 .

3. R. A. Sutherland and F. M. G. Tack, Anal. Chim. Acta, 2002, 454, 249.

4. D. Barałkiewicz and J. Siepak, Anal. Chim. Acta, 2001, 437, 11

5. A. Carlosena, D. Prada, J. M. Andrade, P. López, and S. Muniategui, Fresenius J. Anal. Chem., 1996, 355, 289.

6. D. Baralkiewicz and H. Gramowska, Anal. Chim. Acta, 2004, 510, 249

7. J. L. Burguera, M. Burguera, C. Rondon, L. Rodrígues, P.
Carrero, Y. P. de Peña, and E. Burguera, J. Anal. At. Spectrom., 1999, 14, 821.

8. C. J. de Castro Maciel, G. M. Miranda, D. P. de Oliveira, M. E. P. B. de Siqueira, J. N. Silveira, E. M. A. Leite, and J. B. B. da Silva, Anal. Chim. Acta, 2003, 491, 231.

9. E. C. Lima, R. V. Barbosa, J. L. Brasil, and A. H. D. P. Santos, J. Anal. At. Spectrom., 2002, 17, 1523.

10. G. Schlemmer and B. Welz, Spectrochim. Acta, Part B, 1986, 41,1157

11. X.-Q. Shan and B. Wen, J. Anal. At. Spectrom., 1995, 10, 791.

12. D. L. Tsalev, V. I. Slaveykova, and P. B. Manjukov, Spectrochim. Acta Rev., 1990, 13, 225.

13. A. B. Volynsky, Spectrochim. Acta, Part B, 1998, 53, 139.

14. B. Welz, G. Shlemmer, and J. R. Mudakavi, J. Anal. At. Spectrom., 1992, 7, 1257.

15. E. C. Lima, J. L. Brasil, and A. H. D. P. Santos, Anal. Chim. Acta, 2003, 484, 233

16. P. Bermejo-Barrera, J. Moreda-Piñeiro, A. Moreda-Piñeiro, and A. Bermejo-Barrera, Anal. Chim. Acta, 1998, 368, 281.

17. D. L. Tsalev and V. I. Slaveykova, J. Anal. At. Spectrom., 1992, 7, 147.

18. N. N. Meeravali and S. J. Kumar, J. Anal. At. Spectrom., 2002, 17, 704.

19. H.-H. Lu and S.-J. Jiang, Anal. Chim. Acta, 2001, 429, 247.

20. K. Matsusaki, K. Okada, T. Oishi, and T. Sata, Anal. Sci., 1994, 10, 281.

21. N. Campillo, I. Lopez-Garcia, P. Vinas, I. Arnau-Jerez, and M. Hernandez-Gordoba, J. Anal. At. Spectrom., 2002, 17, 1429.

22. E. C. Lima, F. Barbosa, Jr., F. J. Krug, M. M. Silva, and M. G. R. Vale, J. Anal. At. Spectrom., 2000, 15, 995.

23. P. Grinberg, R. C. Campos, and R. E. Sturgeon, J. Anal. At. Spectrom., 2002, 17, 693.

24. D. L. Tsalev, T. A. Dimitrov, and P. B. Mandjukov, J. Anal. At. Spectrom., 1990, 5, 189.

25. K. Matusaki, T. Yamaguchi, and Y. Yamamoto, Anal. Sci., 1996, $12,301$.

26. M. Y. Shiue, J. Mierzwa, and M. H. Yang, J. Anal. At. Spectrom., 2001, 16, 1172.

27. H.-L. Sun, C.-C. Shiue, and S.-J. J. Tsai, J. Anal. At Spectrom., 2001, 16, 838 .

28. J. P. Byrne, C. C. Chakrabarti, G. F. R. Gilchrist, M. M Lamoureux, and P. Bertels, Anal. Chem., 1993, 65, 1267.

29. Y.-C. Li and S.-J. Jiang, Anal. Chim. Acta, 1998, 359, 205.

30. P. B. Barrera, M. A. Somoza, R. M. S. Ferreiro, and R. D. Gonzalez, Analyst, 1993, 118, 665.

31. Commission on Spectrochemical and Other Optical Procedures for Analysis, Nomenclature, Symbols, Units and Their Usage in Spectrochemical Analysis: II. Data Interpretation, Spectrochim. Acta, Part B, 1978, 33, 241. 